\title{
Stability Enhancement of a Power System Containing High-Penetration Intermittent Renewable Generation
}

\author{
Jorge Morel', Shin'ya Obara, Yuta Morizane \\ Department of Electrical and Electronic Engineering, Kitami Institute of Technology, Kitami, Japan \\ e-mail: jmorel@mail.kitami-it.ac.jp
}

Cite as: Morel, J., Obara, S., Morizane, Y., Stability Enhancement of a Power System Containing High-Penetration Intermittent Renewable Generation, J. sustain. dev. energy water environ. syst., 3(2), pp 151-162, 2015, DOI: http://dx.doi.org/10.13044/j.sdewes.2015.03.0012

\begin{abstract}
This paper considers the transient stability enhancement of a power system containing large amounts of solar and wind generation in Japan. Following the Fukushima Daiichi nuclear disaster there has been an increasing awareness on the importance of a distributed architecture, based mainly on renewable generation, for the Japanese power system. Also, the targets of $\mathrm{CO}_{2}$ emissions can now be approached without heavily depending on nuclear generation. Large amounts of renewable generation leads to a reduction in the total inertia of the system because renewable generators are connected to the grid by power converters, and transient stability becomes a significant issue. Simulation results show that sodium-sulfur batteries can keep the system in operation and stable after strong transient disturbances, especially for an isolated system. The results also show how the reduction of the inertia in the system can be mitigated by exploiting the kinetic energy of wind turbines.
\end{abstract}

\section{KEYWORDS}

Transient stability, Renewable energy, Wind power, Solar power, Tidal power, Storage system, Sodium-sulfur battery.

\section{INTRODUCTION}

Driven by an urgent need of $\mathrm{CO}_{2}$ emission reduction and a strong public opinion resisting nuclear power generation following the Fukushima Daiichi nuclear disaster in 2011, Japan now has the challenge to rebuild and adapt its power system to increase its reliability and resiliency in case of natural disasters. The considered approach is based mainly on the deployment of intermittent and clean renewable energy generation, with a less centralized structure. The Japanese government has established policies to address this issue [1].

The United States of America and the European Union, in contrast, have been implementing policies to reduce $\mathrm{CO}_{2}$ emissions by utilizing renewable energy sources even before the disaster of 2011 [2,3].

Microgrids have evolved as a type of architecture that makes possible the generation and consumption of energy in limited and well defined areas. Their flexibility can make microgrids an active part of a larger smart grid system. Another important benefit of constructing a self-sufficient microgrid is the reduction of power to be transferred over a long distance from where centralized power plants are normally located. This reduces the losses and congestion in the transmission lines. Besides the possibility of interconnection of variable output renewable generators, there are other benefits such as increased

\footnotetext{
* Corresponding author
} 
participation of customers in the reduction of peak demands for the entire system as well as participation in the electricity market [4].

Among the leading research teams in the field of clean energy systems is Aalborg University in Denmark, with the development of an energy system analysis tool called EnergyPLAN [5, 6]. Several studies have been performed in the design of energy systems for specific regions in Europe [7,8] where not only electrical aspects were considered but also heat and transportation. This view is much wider than the case of smart grids alone. However, most of this work focuses on long-term operations and planning, and do not consider the dynamics of the system for normal operating condition and for the case of transient events in the electrical system.

Despite the slower development of smart energy systems in Japan, great effort has been put in by certain research groups before the nuclear disaster of 2011 [9, 10]. Recently, research activities on independent microgrids for local generation and local consumption, containing sustainable renewable energy generation such as wind, solar and tidal power have increased considerably. Operation of microgrids, aiming at the reduction of $\mathrm{CO}_{2}$ emissions and the safety of energy supply, in cold, urban and remote areas has been studied [11-13].

In microgrids, there is a need to match instantaneous imbalances, not only for transient events in the system but also for the fast oscillations of the power outputs of renewable generators by the utilization of fast acting batteries, such as the sodium-sulfur $(\mathrm{NaS})$ battery. Reference 14 analysed the utilization of $\mathrm{NaS}$ batteries in suppressing instantaneous or fast changing impacts in the grid, as well the possibility of independent active and reactive power control in this type of storage systems.

Storage systems have been also analysed from economic and environmental points of view [15, 16]. In [15], NaS batteries are compared to a storage system based on organic chemical hydride. However, the dynamic performance (fast charging/discharging capability) of the $\mathrm{NaS}$ battery should also be considered for a more complete analysis. In Reference 16, a system with no storage is analysed. Here, good $\mathrm{CO}_{2}$ reductions are obtained despite the absence of the battery. However, for a $100 \%$ renewable supply, batteries may be necessary to shift energy between seasons or to keep frequency balance, as well as to compensate for any transient faults in the system.

For a complete analysis of a power grid, the consideration of dynamic properties of supply and demand, especially for transient events, are of vital importance. This is particularly important because of the reduction in the system inertia as wind turbines are connected to the power system through converters, which decouple the inertia of the rotating mass from the system. All the energy system designs mentioned above do not consider this aspect.

The objective of this work is to evaluate the effect of fast acting NaS batteries in the transient stability of a power system containing high penetration of renewable sources with highly variable outputs and with potential to exert strong disturbances on the system (e.g., disconnection of wind turbines due to storms) and reduced system inertia. In order to achieve this, digital simulations are performed using Matlab/Simulink.

Results of this work show that fast acting NaS batteries improve the stability level of the system, keeping the system stable after strong transient disturbances, especially for the case of isolated operation. NaS batteries can also be used for short-term balance between supply and demand during normal operating condition.

\section{STUDY SYSTEM}

In this section, the location of the study area, Kitami City, and the components of the target power system are described. 


\section{Location}

Kitami City is located in a cold region, on the Hokkaido Island in the northern part of Japan, as shown in Figure 1. Kitami has an annual demand characteristic with a high heat-to-power demand ratio during winter. The temperature reaches a minimum of $-20{ }^{\circ} \mathrm{C}$ in winter and a maximum of $35^{\circ} \mathrm{C}$ in summer. Despite the low temperature in winter, the city gets little rainfall and snowfall. Kitami has rich natural resources such as wind, solar and tidal power that can be utilized for the generation of clean electrical energy. It is one of the richest areas in solar radiation in Japan. Also, it has open areas with good average wind speeds which can be exploited for the generation of electricity. The currents in the channels connecting the Saroma Lake and the Sea of Okhotsk offer the possibility for tidal generation [17].

\section{Transmission network}

The Japanese electricity industry consists of ten power companies that supply energy to specific and semi-independent regions. They are interconnected (except Okinawa Electric Power Company) through transmission lines with limited capacities. The Hokkaido Electric Power Company (HEPCO), shown in Figure 1, with a total installed capacity of 7,500 MW, supplies power to the Hokkaido Island, where Kitami City is located. HEPCO is connected to Tohoku Electric Power Company, located in Honshu by a High-Voltage Direct Current (HVDC) transmission system (indicated by a double line in Figure 1), with a capacity of 600 MW, approximately 8\% of HEPCO's total installed capacity [18].

The Kitami City power system is connected to the local utility HEPCO which currently provides the power for the entire city. The simplified scheme of the Kitami's power system considered for simulation, including the proposed location of renewable generators and storage systems, is depicted in Figure 2. The names and rated capacities of the substations are shown in Table 1.

Selection of the location of the renewable generators was made based on available resources in the area. The location of the $\mathrm{NaS}$ batteries was selected to be the Rubeshibe substation where the bulk power comes from the conventional power plants of HEPCO. This selection has no direct effect in the results of the transient stability analysis presented in this paper because of the short distances involved. However, from an economical point of view, the most appropriate locations and sizes must be carefully considered.

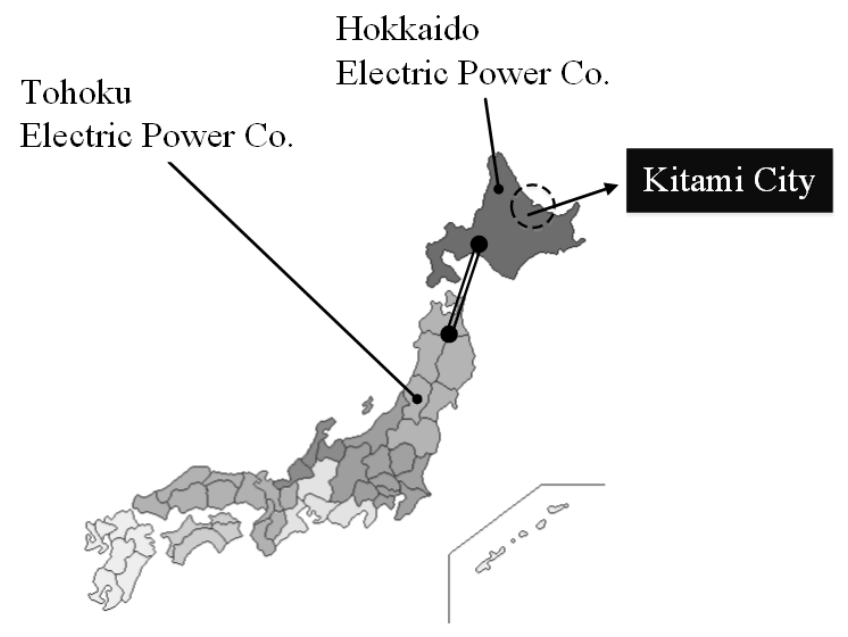

Figure 1. Kitami City location 


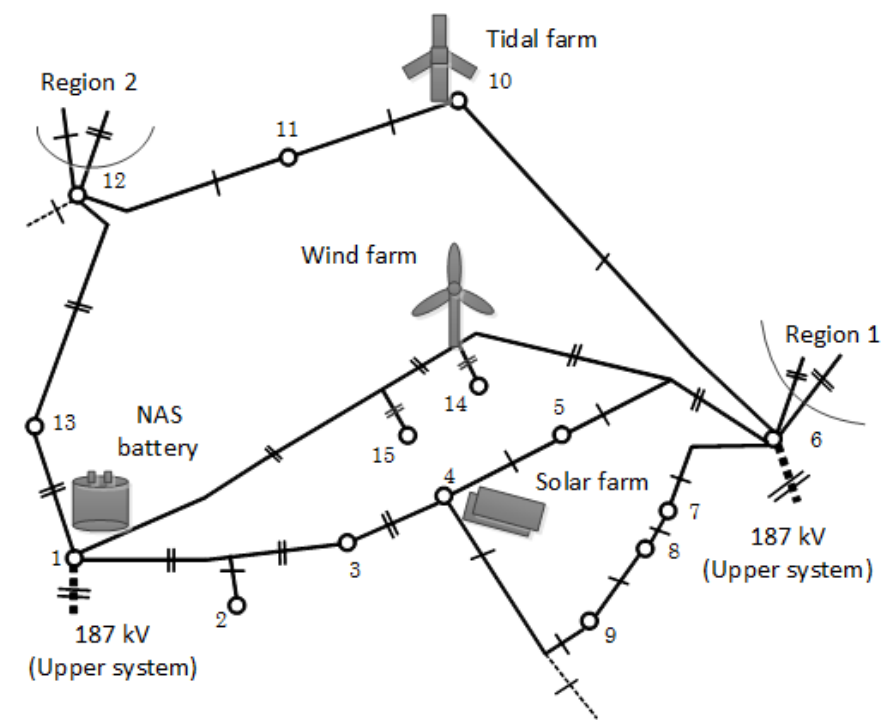

Figure 2. Power system of Kitami City

Table 1. Substation rated capacities

\begin{tabular}{ccc}
\hline No. & Name & Capacity [MVA] \\
\hline 1 & Rubeshibe & 280 \\
2 & Kuneppu & 6 \\
3 & Kitaminishi & 20 \\
4 & Kitami & 35 \\
5 & Tabata & 22 \\
6 & Memanbetsu & 200 \\
7 & Bihoro & 20 \\
8 & Inami & 10 \\
9 & Tsubetsu & 12 \\
10 & Tokoro & 12 \\
11 & Saroma & 10 \\
12 & Engaru & 18 \\
13 & Ikutahara & 3 \\
14 & Kiyomi & 30 \\
15 & Ainonai & 12 \\
\hline
\end{tabular}

As shown in Figure 2, there are mainly two points of connection to the local utility: The Rubeshibe and the Memanbetsu substations. Each of them is supplied by a double-circuit transmission line of $187 \mathrm{kV}$. Region 1 and Region 2 shown in this figure are two systems with no generating units. The total load for Region 1 is 124 MVA and that for Region 2 is 87 MVA. The two thin dashed lines represent the two weak connections to other systems which are not considered in this work. The small circles represent substations and single or double-circuit transmission lines are indicated by one or two transversal short lines over the lines connecting the substations. All lines are overhead with rated voltage of $66 \mathrm{kV}$ and lengths of less than $40 \mathrm{~km}$. Typical tower and conductor data for $66 \mathrm{kV}$ transmission line is considered. Each substation is composed of $66 \mathrm{kV} / 6.6 \mathrm{kV}$ step-down transformers with the rating indicated in Table 1 . The reactive power of the loads is assumed to be compensated since it does not affect the present transient stability analysis. 


\section{Renewable generation}

The three types of renewable generation considered in this work are wind, solar and tidal power.

Wind power. Currently, most Wind Turbines (WTs) in the market are variable-speed types: Doubly-Fed Induction Generator (DFIG) and Full-Scale Converter types, which are capable of independently controlling active and reactive power injected to the system. In this work, the wind farm is simulated using an aggregated model of DFIG-based WTs, modelled by Matlab/Simulink.

Solar power. Photovoltaic type solar farms are considered. They are connected to the transmission network via inverters which also may have the capability of independently controlling the amount of reactive power injected to the network for voltage regulation purposes. This can be exploited conveniently especially for isolated systems. Since for frequency study purposes the faster dynamics are not considered, in this work the solar farm is modelled as a first order system with a short time constant of 10 microseconds.

Tidal power. Horizontal axis tidal turbines are considered [19]. They have similar structure and working principle as the WTs [20, 21]. For short-term frequency studies the tidal turbines can be assumed to have constant power output. For long-term studies the variability can be forecasted with a high degree of accuracy. The tidal farm is simulated using an adapted version of the DFIG-based WT. These assumptions are valid due to the similarity between the wind and tidal generation systems and the time scale considered for simulation.

Horizontal wind turbines and horizontal tidal turbines have essentially the same structure: A rotor composed of blades, connected to a generator. The rotor is in charge of transforming the kinetic energy of the incoming fluid into rotating mechanical energy. The generator is in charge of transforming the mechanical energy of the rotor into electricity. The differences in both types of turbines are mainly due to the interaction between the fluids with different densities, i.e. wind and water, with the rotor. For the same rated power, a tidal turbine will have smaller rotor diameter than a wind turbine [21].

The DFIG structure is the same in both types of turbines. The generator is connected to the power grid through the stator and through the rotor. The connection of the stator is made directly or via a transformer, and that of the rotor is made by a back-to-back converter, with or without a transformer. This arrangement allows control of the electrical torque by the rotor side converter in order to adjust the rotational speed of the rotor according to wind speed variations to improve energy absorption efficiency. The detailed modelling of a tidal turbine including equations, similarities and differences with wind turbines can be found in [20,21].

The parameters of the renewable generators are shown in Table 2.

Table 2. Aggregated renewable generator parameters

\begin{tabular}{ccc}
\hline Generation & $\begin{array}{c}\text { Rated capacity } \\
{[\mathrm{MVA}]}\end{array}$ & $\begin{array}{c}\text { Point of connection } \\
(\text { No. })\end{array}$ \\
\hline Wind farm & 150 & Kiyomi (14) \\
Solar farm & 100 & Kitami (4) \\
Tidal farm & 1.5 & Tokoro (10) \\
\hline
\end{tabular}




\section{Storage systems}

For long-term energy storage aiming at the seasonal and daily energy shifting, a storage system with slow dynamics but with high energy density should be utilized. For seasonal energy shifting, an organic chemical hydride type system can be employed [15].

For instantaneous and fast demand-supply imbalance compensation $\mathrm{NaS}$ batteries are employed due to their fast charge-discharge capability. They have been satisfactorily applied in the levelling of power outputs fluctuations of wind farms. They also can be used for load levelling and load peak shaving [22, 23].

In this work, a simplified model of the NaS battery is considered. A first order system with a small time constant of 10 microseconds, to represent the fast dynamics of this type of batteries, is considered.

\section{CONTROL STRATEGY}

For both normal and fault condition control strategies a Model Predictive Control (MPC) approach is considered for the control of the $\mathrm{NaS}$ batteries. Due to the uncertainty and randomness involved in the study system, MPC is used as it can handle multiple inputs and multiple outputs, in contrast to conventional proportional-integral controllers $[24,25]$. Inertial control approach by WTs [26] provides primary frequency support to mitigate the reduced system inertia. The overall control strategy is shown in Figure 3.

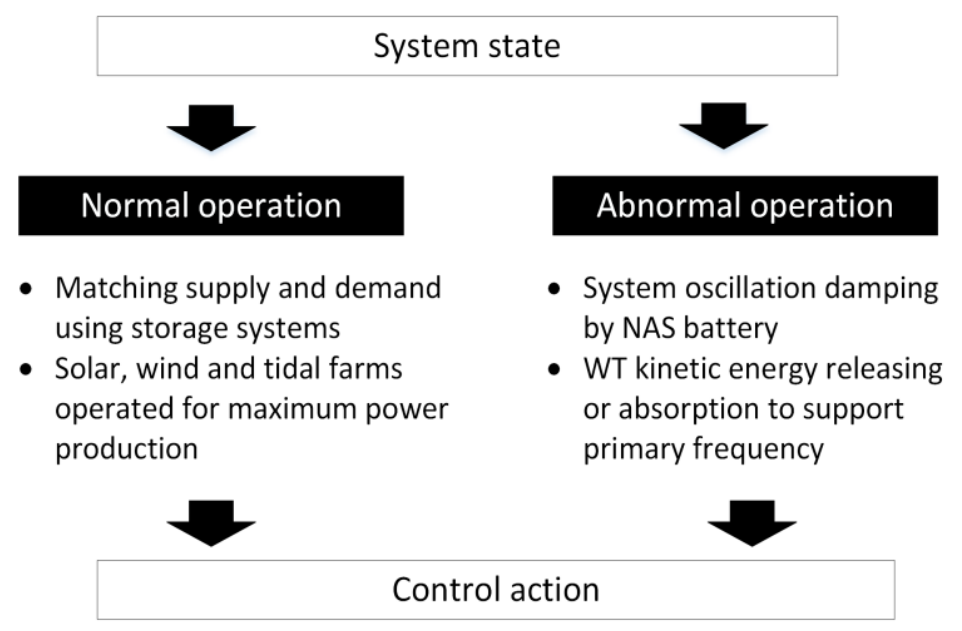

Figure 3. Overall control strategy

\section{Normal condition}

During normal condition, the WTs are controlled for maximum power absorption and maximum power output, and to limit the power output during high-speed wind conditions by applying pitch control. A similar control strategy is considered for the tidal farm. The solar farm is operated for maximum power generation. The $\mathrm{NaS}$ batteries are controlled to match supply and demand in the system to keep frequency within permitted ranges.

\section{Abnormal condition}

In case of abnormal or fault condition, the NaS batteries and the wind farm are operated with different strategies. Wind turbines are allowed to release or absorb, temporarily, kinetic energy by their rotating parts in order to mitigate the reduced inertia of the system and to support the primary frequency control. At the same time, battery output is entirely devoted to damp the fast oscillations of the system by absorbing or injecting active power to the network. 


\section{BUILDING OF THE SCENARIOS}

Dynamic simulations are performed for three different scenarios to evaluate the effects of fast charging-discharging batteries in reducing the frequency oscillations and stabilizing the system: Target system connected to the local utility (Scenario 1), target system isolated from the local utility (Scenario 2) and primary frequency support by WTs (Scenario 3).

Scenario 1 considers the target power grid connected to that of HEPCO at two points: Rubeshibe and Memanbetsu substations. At these points, two aggregated generator models simulate the synchronous generators of the rest of the system. These generators also perform voltage and frequency control tasks.

In Scenario 2 the target power system is considered completely isolated from that of HEPCO. Only small hydropower stations in the order of 80 MVA remained connected to the system. Since there is a considerable reduction of the inertia of the system, a more severe effect is expected during transient events.

Scenario 3 shows the effect of the support provided by WTs to the network frequency during disturbances, such as in the case of a loss of an important load in the system. This scenario evaluates this WT capability assuming that the battery's stored energy level is not enough to allow any additional charge-discharge operation. A loss of $10 \%$ of the system's load is considered and the frequency profiles are analysed. The target system is assumed connected to the local utility HEPCO.

Two cases are considered for Scenarios 1 and 2: Loss of wind generation due to a storm (Case 1) and three-phase-to-ground-fault (Case 2).

In Case 1, a strong storm is assumed to affect the area where the wind farms are located. A step increase in the wind speed at $t=20 \mathrm{~s}$ is followed by the disconnection of the WTs at $t=30 \mathrm{~s}$ caused by the wind speed exceeding the cut-out wind speed level, as shown in Figure 4.

In Case 2, a three-phase-to-ground fault, with a duration of 5 cycles, is considered in the grid at $t=35 \mathrm{~s}$, causing strong oscillations in the synchronous units of the system.

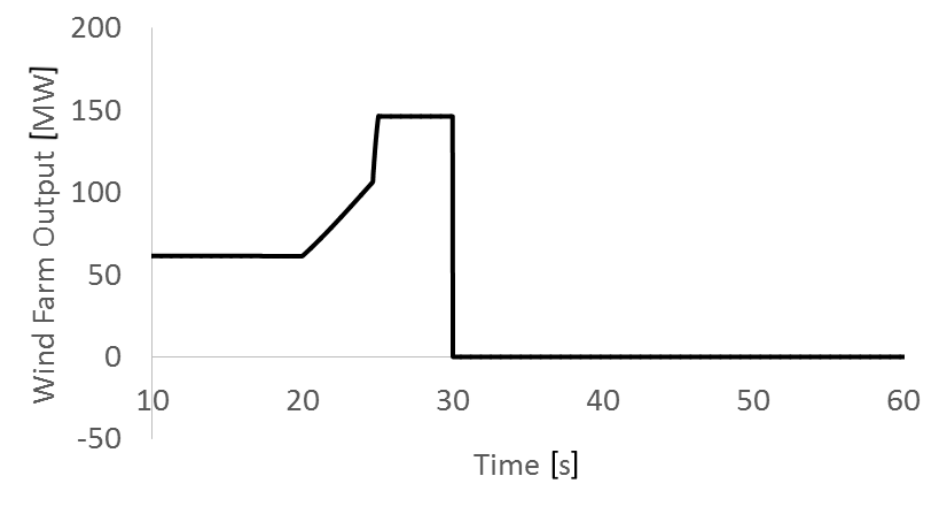

Figure 4. Wind farm power output

\section{SIMULATION RESULTS}

The overall scheme of the Matlab/Simulink model utilized for simulation is shown in Figure 5. In this figure the Wind Farm (WF), the Solar Farm (SF), the Tidal Farm (TF), the NaS battery, the two aggregated generators (HEPCO-Rubeshibe and HEPCO-Memanbetsu), together with the MPC controller are shown. The measured output (mo) is the frequency of the system (FREQ) with a reference setting of $50 \mathrm{~Hz}$ and the measured disturbances (md) are the WF, TF and SF outputs. The manipulated 
variable (mv) is the corresponding setting of the NaS battery active power. Reactive power setting of the $\mathrm{NaS}$ battery was considered equal to zero.

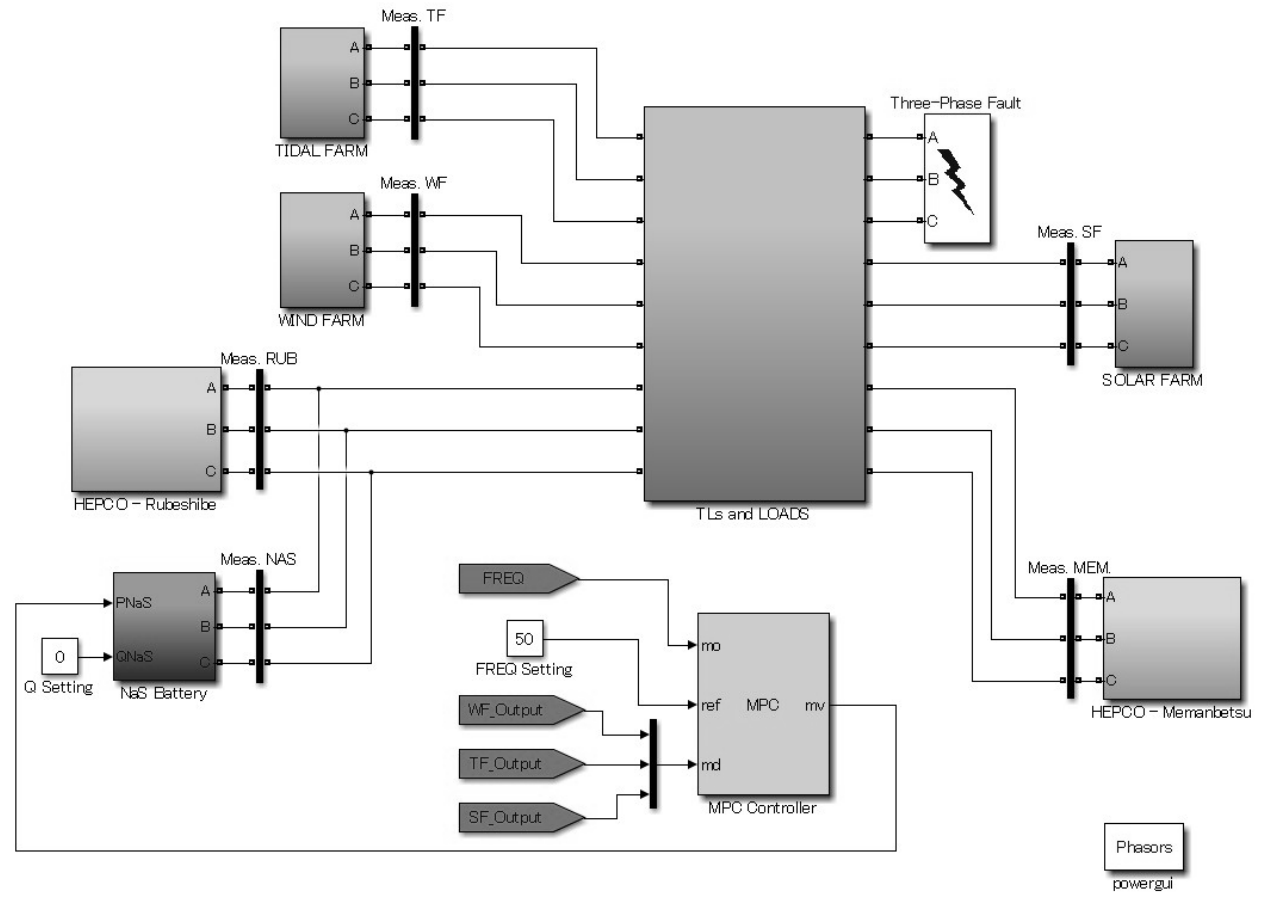

Figure 5. Matlab/Simulink model diagram

\section{Scenario 1: Target system connected to the local utility}

Case 1: Loss of wind generation due to a storm. In order to assess the stability level of the system, synchronous machine speed deviations are analysed with and without the support of the proposed control scheme. In per unit values, the speed deviations are equal to the frequency deviations. Figure 6 shows the variations in the system's frequency at Rubeshibe substation for this scenario. Without the support of the NaS batteries, the systems experiences instability. Using the fast acting batteries completely avoids the instability.

Case 2: Three-phase-to-ground fault. As shown in Figure 7, the utilization of the NaS batteries allows faster damping of these oscillations, recovering the normal frequency level, compared to the case without batteries.

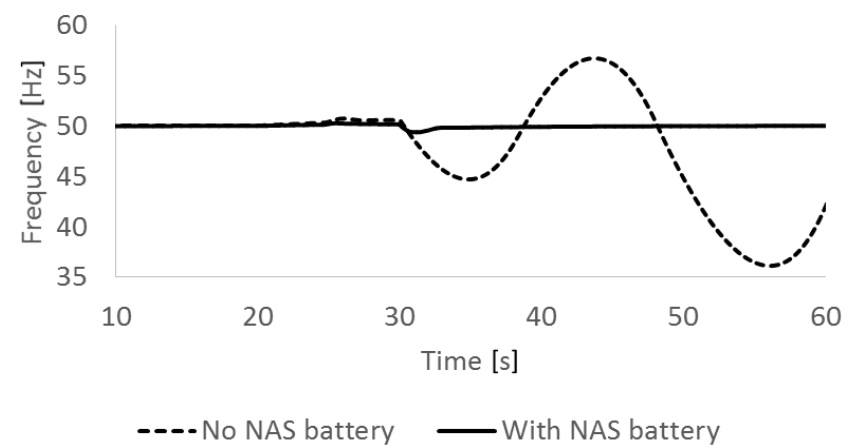

Figure 6. Frequency for loss of wind generation - Scenario 1 


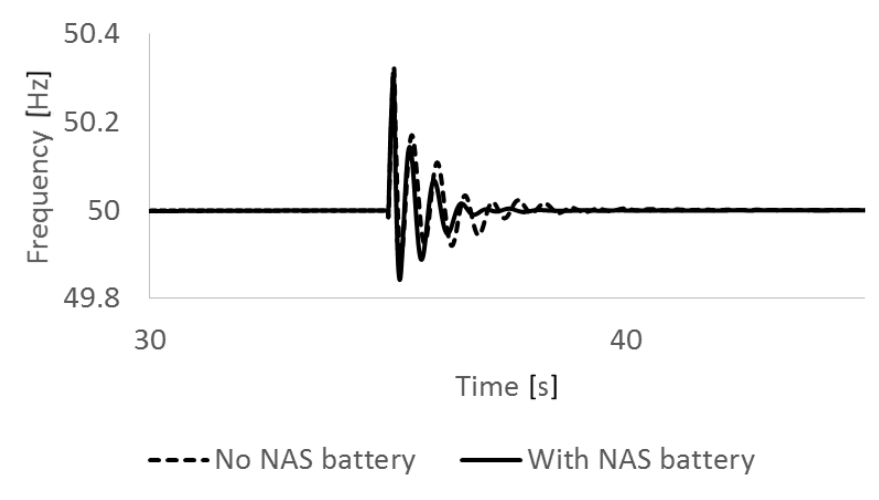

Figure 7. Frequency for fault condition - Scenario 1

\section{Scenario 2: Target system isolated from the local utility}

Case 1: Loss of wind generation due to a storm. Figure 8 shows the variations in the system frequency at Rubeshibe substation. As can be noticed, the system experiences instability if the NaS batteries are not in operation.

Case 2: Three-phase-to-ground fault. Results in Figure 9 shows that with the NaS batteries in operation the oscillations are damped completely, recovering the normal frequency level, faster than in the case when the system is not provided with this support.

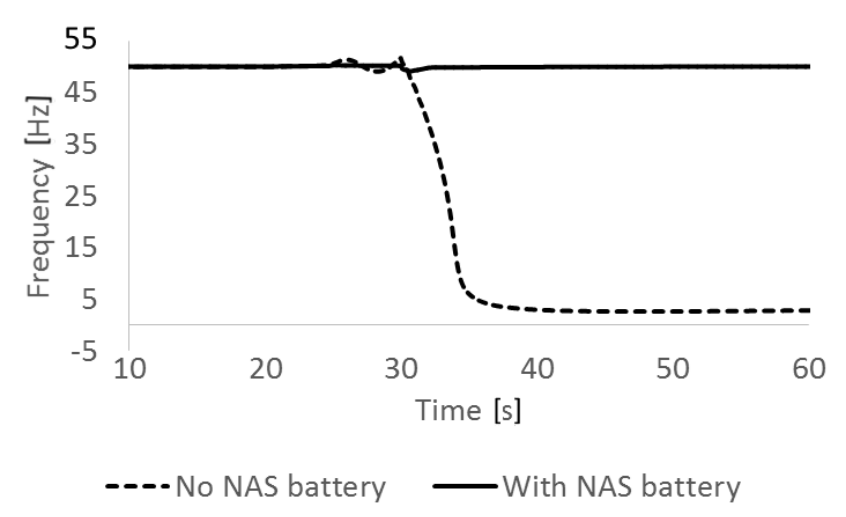

Figure 8. Frequency for loss of wind generation - Scenario 2

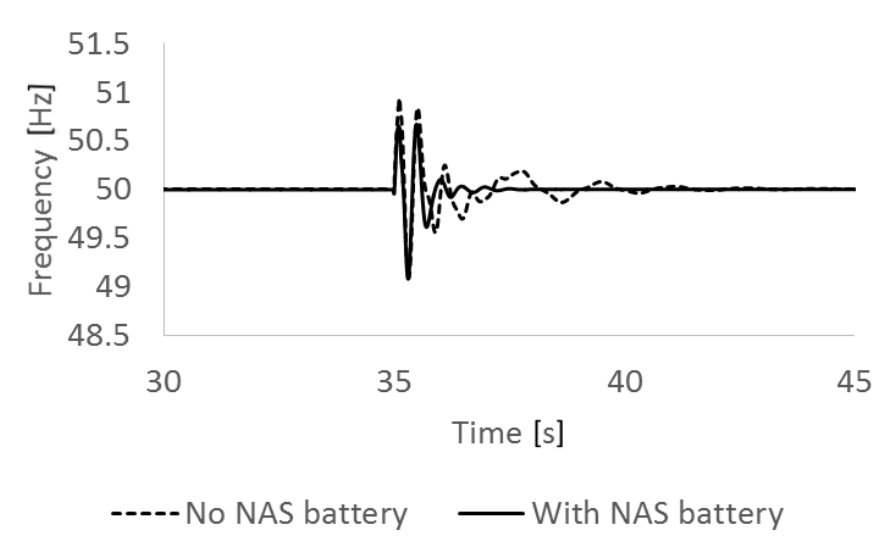

Figure 9. Frequency for fault condition - Scenario 2 


\section{Scenario 3: Primary frequency support by wind turbines}

Variable speed WTs are able to release or absorb kinetic energy by their rotating parts, temporarily and almost instantaneously after a disturbance in the system, emulating the dynamics of synchronous generators and contributing to the recovery of the system's frequency. This is achieved by additional control loops to regulate WT's power output. The support of WTs is particularly useful when the level of stored energy in the NaS batteries is not adequate for proper charging-discharging operation to support system's frequency.

Figure 10 shows the primary frequency profile of the system for this scenario, with and without WT support. It can be seen that the WTs reduce the impact of a load change in the system by absorbing kinetic energy, just after the disturbance, damping the frequency peak at this point.

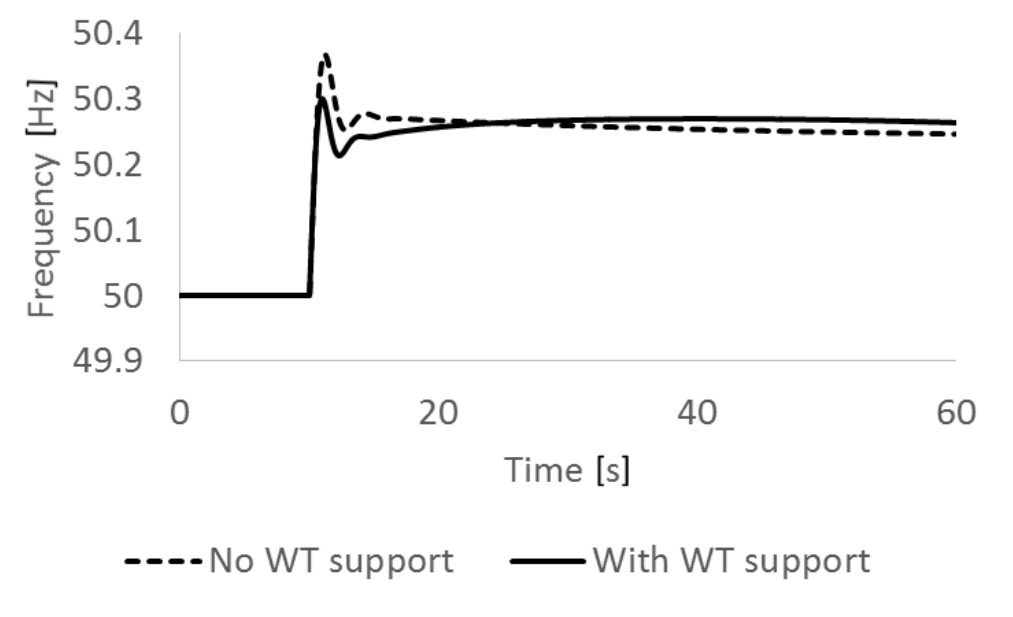

Figure 10. Frequency for loss of load - Scenario 3

\section{CONCLUSION}

This paper introduced a strategy to improve the transient stability of a power system with a high-penetration of intermittent renewable sources. The stability degradation arises mainly due to the highly variable outputs of these types of generators, during normal and abnormal operations (e.g., disconnection of wind turbines due to a storm). Reduction in the system's total inertia because of the connection of renewable generators, connected through power converters that decouple the dynamics of the generators from that of the system, also degrades system stability.

Three scenarios were considered: First, the target power system was considered connected to the local public utility, and secondly, the target power system was considered isolated. Each of these two scenarios was studied with two types of disturbances in the system: disconnection of an important wind farm due to a storm and a three-phase-to-ground fault in the power network. Finally, a third scenario was presented to demonstrate that the wind turbines can damp oscillations in the frequency by absorbing electrical energy in their rotating parts for the case of a loss of an important load in the system.

Results show that the proposed scheme, designed to charge and discharge the NaS batteries according to the oscillations in the system, and to make wind turbines participate in primary frequency support, improved the stability level by considerably reducing the synchronous machine oscillations, keeping the system operating and stable for the various scenarios presented. 
In the case of more strict conditions that characterize isolated operation, voltage stability analysis must also be carefully evaluated for a more complete study of the overall stability level of the system.

\section{REFERENCES}

1. Ministry of Economy, Trade and Industry (METI), Annual Report on Energy, Outline of the FY2012 Annual Report on Energy (Energy White Paper 2013), http://www.meti.go.jp/english/report/index_whitepaper.html\#energy, [Accessed: 24-February-2014]

2. U.S. Department of Energy, Mission, http://www.energy.gov/mission, [Accessed: 24-February-2014]

3. European Commission, Energy Strategy for Europe, http://ec.europa.eu/energy/index_en.htm, [Accessed: 24-February-2014]

4. SmartGrid.gov, What is a Smart Grid? https://www.smartgrid.gov/the_smart_grid\#smart_grid, [Accessed: 24-February-2014]

5. EnergyPLAN, Advanced Energy System Analysis Computer Model, Aalborg University, http://www.energyplan.eu/about/, [Accessed: 24-February-2014]

6. Lund, H., Andersen, A. N., Østergaard, P. A., Mathiesen, B. V., Connolly, D., From Electricity Smart Grids to Smart Energy Systems - A Market Operation Based Approach and Understanding, Energy - The International Journal, Elsevier, Vol. 42, No. 1, pp 96-102, 2012, http://dx.doi.org/10.1016/j.energy.2012.04.003

7. Connolly, D., Lund, H., Mathiesen, B. V., Werner, S., Möller, B., Persson, U., Boermans, T., Trier, D., Østergaard, P. A., Nielsen, S., Heat Roadmap Europe: Combining District Heating with Heat Savings to Decarbonise the EU Energy System, Energy Policy, Elsevier, Vol. 65, pp 475-489, 2014, http://dx.doi.org/10.1016/j.enpol.2013.10.035

8. Connolly, D., Lund, H., Mathiesen, B. V., Leahy, M., The First Step Towards a 100\% Renewable Energy-system for Ireland, Applied Energy, Elsevier, Vol. 88, No. 2, pp 502-507, 2011, http://dx.doi.org/10.1016/j.apenergy.2010.03.006

9. Obara, S., Development of a Dynamic Operational Scheduling Algorithm for an Independent Micro-Grid with Renewable Energy, Journal of Thermal Science and Technology, The Japan Society of Mechanical Engineers (JSME), Vol. 3, No. 3, pp 474-485, 2008, http://dx.doi.org/10.1299/jtst.3.474

10.U. S. Department of Energy, Microgrids at Berkeley Laboratory, Nagoya 2007 Symposium on Microgrids, Overview of Micro-grid R\&D in Japan, http://der.lbl.gov/sites/der.lbl.gov/files/nagoya_morozumi.pdf, [Accessed: 25-February-2014]

11.Cellura, M., Di Gangi, A., Orioli, A., Assessment of Energy and Economic Effectiveness of Photovoltaic Systems Operating in a Dense Urban Context, Journal of Sustainable Development of Energy, Water and Environment Systems, Issue 1, No. 2, pp 109-121, 2013, http://dx.doi.org/10.13044/j.sdewes.2013.01.0008

12.Quoilin, S., Orosz, M., Rural Electrification through Decentralized Concentrating Solar Power: Technological and Socio-Economic Aspects, Journal of Sustainable Development of Energy, Water and Environment Systems, Issue 1, No. 2, pp 199-212, 2013, http://dx.doi.org/10.13044/j.sdewes.2013.01.0015

13.Obara, S., Kawai, M., Kawae, O., Morizane, Y., Operational Planning of an Independent Microgrid Containing Tidal Power Generators, SOFCs, and Photovoltaics, Applied Energy, Elsevier, Vol. 102, pp 1343-1357, 2013, http://dx.doi.org/10.1016/j.apenergy.2012.07.005 
14.Ohtaka, T., Iwamoto, S., A Method for Suppressing Line Overload Phenomena Using NaS Battery Systems, Electrical Engineering in Japan, Wiley, Vol. 151, No. 3, pp 19-31, 2005, http://dx.doi.org/10.1002/eej.20102

15.Obara, S., Morizane, Y., Morel, J., Economic Efficiency of a Renewable Energy Independent Microgrid with Energy Storage by a Sodium-Sulfur Battery or Organic Chemical Hydride, International Journal of Hydrogen Energy, Elsevier, Vol. 38, No. 21, pp 8888-8902, 2013, http://dx.doi.org/10.1016/j.ijhydene.2013.05.036

16.Obara, S., Morel, J., Microgrid Composed of Three or More SOFC Combined Cycles without Accumulation of Electricity, International Journal of Hydrogen Energy, Elsevier, Vol. 39, No. 5, pp 2297-2312, 2014, http://dx.doi.org/10.1016/j.ijhydene.2013.11.102

17.Japan Meteorological Agency, http://www.jma.go.jp/jma/indexe.html, [Accessed: 26-February-2014]

18.Hokkaido Electric Power Company, Main Infrastructure, http://www.hepco.co.jp/corporate/ele_power/ele_power.html, [Accessed: 26-February-2014] (In Japanese)

19.Tocardo Tidal Turbines, http://www.tocardo.com/, [Accessed: 26-February-2014]

20.Aly, H. H. H., El-Hawary M. E., Comparative Study of Stability Range of Proposed PI Controllers for Tidal Current Turbine Driving DFIG, International Journal of Renewable and Sustainable Energy, Vol. 2, No. 2, pp 51-62, 2013, http://dx.doi.org/10.11648/j.ijrse.20130202.15

21.Ben Elghali, S. E., Benbouzid, M. E. H., Charpentier, J. F., Modeling and Control of a Marine Current Turbine Driven Doubly-Fed Induction Generator, IET Renewable Power Generation, Vol. 4, No. 1, pp 1-11, 2010, http://dx.doi.org/10.1049/iet-rpg.2008.0118

22.Tanaka, K., Kurashima, Y., Tamakoshi, T., Recent Sodium Sulfur Battery Application in Japan, Bonneville Power Administration, http://www.bpa.gov/Energy/n/tech/energyweb/docs/Energy\%20Storage/NGK-Paper.P DF, [Accessed: 26-February-2014]

23.NGK Insulators Ltd, http://www.ngk.co.jp/english/products/power/nas/, [Accessed: 26-February-2014]

24.Bemporad, A., Morarim M., Ricker N. L., Model Predictive Control Toolbox User's Guide, The MathWorks, Inc., 1998.

25.Ernst, D., Glavic, M., Capitanescu, F., Wehenkel, L., Reinforcement Learning Versus Model Predictive Control: A Comparison on a Power System Problem, IEEE Transactions on Systems, Man, and Cybernetics, Vol. 39, No. 2, pp 517-529, 2009, http://dx.doi.org/10.1109/TSMCB.2008.2007630

26.Mauricio, J. M., Marano, A., Gomez-Exposito A., Martinez Ramos J. L., Frequency Regulation Contribution Through Variable-Speed Wind Energy Conversion Systems, IEEE Transactions on Power Systems, Vol. 24, No. 1, pp 173-180, 2009, http://dx.doi.org/10.1109/TPWRS.2008.2009398 